\title{
El abastecimiento de grano a las ciudades hispanorromanas. Producción, almacenaje y gestión
}

\section{The grain supply of the Roman towns in Hispania. Production, storage and management}

\author{
Javier Salido Domínguez \\ Escuela Española de Historia y Arqueología en Roma, CSIC
}

\begin{abstract}
RESUMEN
En este trabajo se presentan las últimas novedades sobre el estudio del aprovisionamiento de grano y otros productos agrícolas en las ciudades hispanorromanas. Se pretende abordar la cuestión del abastecimiento, superando la visión que nos ofrecen las fuentes literarias, y centrando su atención en los restos materiales que mejor nos informan sobre la producción, el almacenaje y la redistribución de los alimentos, es decir, los horrea y graneros conservados tanto en el territorio como en el núcleo urbano de las antiguas ciudades romanas. La reinterpretación y análisis de los testimonios epigráficos nos permiten además presentar nuevos planteamientos sobre la gestión del cereal y otros productos alimentarios en las ciudades hispanorromanas.
\end{abstract}

\section{SUMMARY}

This work presents the last updates in the study of grain supply of the Roman towns in Hispania. The purpose of this study is to discuss the issue of provisioning by going beyond the standpoint found in literary sources, and in particular by focusing on horrea and granaries. These remains are considered as the most valuable sources to obtain information related to food production, storage and redistribution. Both granaries and storage buildings preserved in the territory and those preserved in the city centre are included in this study. By reinterpreting and analysing epigraphic testimonies, we present new approaches to address the management of grain in the Roman cities in Hispania.

PALABRAS CLAVES: Abastecimiento, annona, grano, horrea, ciudades, villae, epigrafía.

KEY WORDS: Supply, annona, grain, horrea, towns, villae, epigraphy.

\section{INTRODUCCIÓN}

El estudio del abastecimiento de alimentos a las ciudades hispanorromanas se inicia con los primeros trabajos dedicados al análisis de los mecanismos de administración, organización y control del cereal por parte de Roma ${ }^{1}$. La fuente documental en la que se basan estos primeros trabajos de finales del siglo XIX y comienzos del siglo XX es principalmente textual, lo que convierte el Codex Theodosianus en la obra principal sometida a estudio por todos los especialistas $^{2}$. A partir de estos primeros ensayos, se fueron proponiendo nuevos planteamientos que implicaban el uso de otro tipo de fuentes ya conocidas, como los testimonios arqueológicos, las inscripciones, representaciones en el arte, etc., análisis que vemos reflejado en trabajos como el escrito por Cagnat (1916).

El valor de estas obras reside en que plantean la necesidad de analizar la economía romana a partir de las fuentes de las que disponían y supone el inicio de la investigación de un tema inexistente en la historiografía anterior, que subraya la importancia que tuvo el grano en el Imperio y la cuestión de la eficacia en la gestión de un producto de primera necesidad por

\footnotetext{
${ }^{1}$ Este trabajo se ha realizado en el marco del Proyecto I+D de investigación: Formación y disolución de civitates en el $\mathrm{NO}$ peninsular. Estructuras de poblamiento y territorio ( $\mathrm{Ci}$ vitates) (HAR2008-06018-C03-03), dirigido por la prof. Dña. Carmen Fernández Ochoa y del Proyecto I+D: Campamentos y territorios militares en Hispania (PRATA) (HAR201124095), dirigido por el prof. D. Ángel Morillo. Quería agradecerles a ambos la revisión del texto, y también a D. Mariano Rodríguez por su ayuda al ofrecerme información epigráfica importante para la elaboración de este artículo.

${ }^{2}$ Entre las grandes obras de finales del siglo XIX, se pueden destacar entre otras el artículo publicado en 1870 por Hirschfeld titulado Die Getreideverwaltung in der römischen Kaiserzeit, la tesis de G. Krakauer que publicó en 1874 bajo el título Das Verpflegungswesen der Stadt Rom in der späteren Kaiserzeit, la de E. Gebhardt Studien über das Verpflegungswesen von Rom und Constantinopel in der späteren Kaiserzeit (1881) o la obra de Babled, De la cura annonae chez les Romains (1892).
} 
parte de la administración. Esta línea de investigación ha sido desarrollada en obras posteriores, aunque la mayoría se han centrado en el aprovisionamiento de grano a la ciudad de Roma ${ }^{3}$.

Recientemente se han puesto en valor los restos materiales que de forma más precisa nos informan sobre la producción, el almacenaje y la redistribución de los alimentos, es decir, los horrea, almacenes y graneros conservados tanto en el paisaje rural como en los centros urbanos de las antiguas ciudades romanas. Como resultado de este creciente interés, se han constituido grupos de trabajo encaminados a conocer mejor las técnicas empleadas en su construcción, la administración y los espacios comerciales asociados a estos importantes edificios económicos ${ }^{4}$.

Para el caso hispano, cada vez son más los esfuerzos encaminados a conocer mejor los almacenes y graneros que nos permiten comprender el funcionamiento de la administración orientada al abastecimiento de alimentos y otros productos. Este es el tema de mi investigación doctoral que, tratando de superar las fronteras nacionales, analiza las Estructuras de almacenamiento de cereal en el Occidente del Imperio Romano, cuyos resultados se han publicado parcialmente (Salido 2011) y en otros trabajos centrados en el estudio del aprovisionamiento civil y militar en la antigua Hispania (Salido 2009; 2011b; 2012b; Morillo

\footnotetext{
${ }^{3}$ Entre estas publicaciones, se puede destacar el libro de Chastagnol, La préfecture urbaine à Rome sous le Bas-Empire (1960), la tesis de Alzon, Problèmes relatifs à la location des entrepôts en Droit romain (1964), el trabajo de E. Tengström, Bread for the People (1975) y más recientes como la publicación de Durliat, De la ville antique à la ville byzantine le problème des subsistances (1990), la tesis de Jaidi, L'Afrique et le blé de Rome aux IVème et Vème siecles (1990), Sirks, Food for Rome: the legal structure of the transportation and processing of supplies for the imperial distributions in Rome and Constantinople (1991) o las actas de los coloquios Le ravitaillement en blé de Rome et des centres urbains des débuts de la République jusqu'au Haut Empire (1994) y Nourrir les cités de Méditerranée antiquité-temps modernes (2003).

${ }^{4}$ Entre los grupos de trabajo más importantes debemos destacar el proyecto internacional Entrepôts et lieux de stockage du monde gréco-romain antique, financiado por la Agence Nationale de la Recherche (ANR) y desarrollado por tres instituciones francesas, el Centre Camille Jullian (CCJ), el Institut de Recherche en Architecture Antique (IRAA) y la Ecole Française d'Athènes (EfA) encaminado a investigar el Portus, Ostia, los Horrea Caelia en Túnez y los espacios de almacenaje urbanos en Delos (Grecia), así como el estudio del almacenaje en general. Otro proyecto reciente está encabezado por Renato Sebastiani (Soprintendenza Speciale per i Beni Archeologici di Roma) y tiene el propósito de estudiar la llanura situada junto al río Tíber, al pie del Aventino, que constituyó el área comercial, logística y de abastecimiento alimentario de la capital. También se están desarrollando investigaciones de gran importancia como la promovida por Francesco Martorella en el marco del proyecto GRAWINAE: Granaries and warehouses in north Africa and Egypt during the Roman age. Typology, building techniques, function, productive context.
}

y Salido 2010; Fernández Ochoa et alii 2011). También recientemente se ha publicado la revisión científica Horrea d'Hispanie et de la Méditerranée romaine, aunque hasta el momento no se ha llevado a cabo un análisis de conjunto de la información aportada por los documentos epigráficos y los restos arqueológicos, estudio que pretendemos presentar en este trabajo.

\section{LA PRODUCCIÓN DE CEREAL EN EL AGER DE LAS CIUDADES HISPANORROMANAS}

La fundación de las primeras colonias y la reorganización del territorio en época republicana responden a un programa planificado que supone la reordenación del espacio agrario con el objetivo preciso de establecer una nueva fiscalidad. Como resultado de esa nueva estructuración del terreno, además de la creación de una red viaria, se producirá el surgimiento de las primeras villae en la Península Ibérica ${ }^{5}$. A nivel general, se trata de estructuras rústicas de dimensiones reducidas, dotadas de espacios residenciales modestos, que estaban destinadas a la explotación rural del territorio que previamente había sido asignado a sus propietarios. Como consecuencia, desde su origen las villae eran concebidas como centros de producción. En este sentido, la construcción de un granero rebosante de grano simbolizaba en el espacio rural la posesión de la abundancia, la prosperidad y el bienestar económico (Purcell 1995: 169-170). De hecho, el propio Varrón afirma que el término villa procede de la palabra vehere, es decir, el lugar donde la cosecha era transportada y almacenada ${ }^{6}$. No obstante, no será hasta principios del siglo I d.C. cuando se manifieste la división teórica tripartita de la villa romana planteada por Columela (pars urbana, rustica y fructuaria), que refleja la importancia de la vocación rústica y del espacio de almacenaje de los productos agrícolas dentro de las propiedades de las villae romanas. No obstante, a pesar de la importancia que tuvieron los graneros como edificios más representativos de la verdadera riqueza del propietario $\mathrm{y}$, aunque son el principal testimonio arqueológico que nos informa sobre el almacenaje y producción de dichos centros rurales, la historiografía más reciente apenas ha analizado estas estructuras de carácter productivo (Salido 2003-04; 2008b; 2011b).

\footnotetext{
5 Sobre el debate historiográfico del surgimiento de las $v i$ llae y la explotación del territorio en época republicana, véase los recientes estudios publicados en VV. AA. 2010 y Nolla, Palahí y Vivo 2010.

6 "Vilicus agri colendi causa constitutus atque appellatus a villa, quod ab eo in eam convehuntur fructus et evehuntur, cum veneunt" (Varro. rust. 1, 2, 14).
} 
Estos establecimientos rurales contaban con áreas reservadas al almacenaje de grano en silos, bien documentados en numerosos centros de explotación del territorio del área catalana y del resto de la geografía peninsular (cf. Nolla, Palahí y Vivo 2010: 81-90), y en horrea con pavimentos sobreelevados, que permitían mantener el grano en condiciones ideales de temperatura y humedad a largo plazo. El destino de ese cereal sería el autoabastecimiento de la unidad familiar, la reserva para la cosecha del siguiente año, la venta del excedente de cereal en las ciudades y, por supuesto, la fiscalidad en especie, de modo que gran parte de la producción de estos establecimientos rurales era desviada al $\mathrm{ca}$ put civitatis, donde era consumida. En este sentido, la construcción de graneros sobreelevados se convirtió en un sistema de almacenaje que, aunque no supuso una gran novedad en cuanto a la técnica constructiva, pues era un tipo bien conocido siglos antes (Gracia 2009), sí llegó a convertirse en el modelo de granero más eficaz, pues entre otras muchas ventajas ofrece la posibilidad de abrir y cerrar la cámara de almacenaje tantas veces como se quiera, de modo que se podía hacer entrega del grano en el momento convenido, sin echar a perder el resto del producto conservado.

Los sistemas de almacenaje que más informan sobre la potencialidad agrícola del territorio son evidentemente los graneros sobreelevados (Fig. 1).

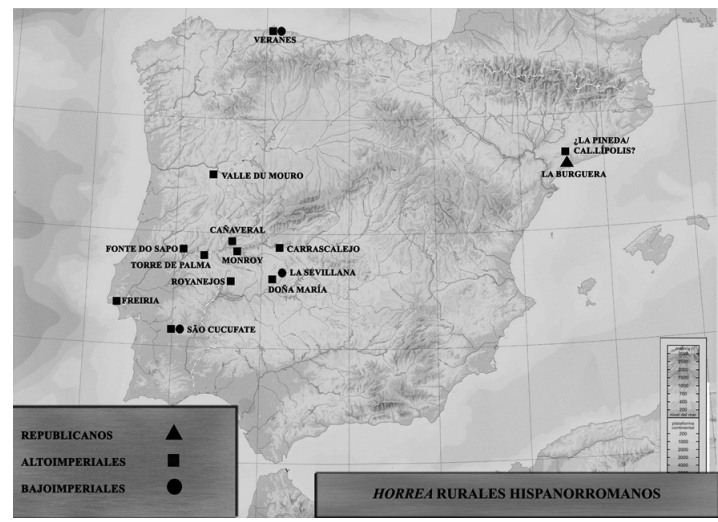

Figura 1. Mapa de dispersión de los principales horrea del ager de las ciudades hispanorromanas.

El hecho de que los establecimientos rurales $a$ priori no contaran con más de un horreum en sus fundi, la mayor facilidad para su identificación desde el punto de vista arqueológico y la posibilidad que nos ofrece de comparar al menos el tamaño de los edificios, hacen de estas las estructuras de almacenaje más susceptibles de ser estudiadas para conocer los centros de acumulación del grano y otros productos alimenticios en el ámbito rural.
Así pues, en el ager de las primeras ciudades, encontramos estructuras que nos informan sobre la producción del cereal que era consumido en las propias ciudades y del aprovisionamiento de las mismas. Es muy posible que las villas se distribuyeran concéntricamente en relación con el caput civitatis y que hubiese una mayor densidad de centros de explotación rural en sus proximidades (Leveau 1983-1984: 920-942). La cercanía a las mismas explica que los horrea de algunos establecimientos rurales cuenten con una escasa capacidad de almacenaje. Este es el caso de la villa de La Burguera, perteneciente al ager Tarraconensis (Macias 2011: 188-189), donde se puso al descubierto el primer horreum sobreelevado rural de piedra descubierto en Hispania (Salido 2011b: 133), fechado en la segunda mitad del siglo I a.C. El tipo constructivo se asemeja a otras edificaciones de esta funcionalidad, con cinco muros paralelos que permiten sobreelevar el pavimento de madera o tabulatum sobre el que se vertería el cereal.

En el territorio de la antigua ciudad de Gijón, se halla el establecimiento rural de Veranes (Fig. 2) (Fernández Ochoa 2000: 164-171; Fernández Ochoa et alii 2004; Fernández Ochoa y Gil Sendino 2008), a unos 800 metros del ramal transmontano de la vía de la Plata que comunicaba la antigua ciudad de Gijón con Lucus Asturum y Asturica Augusta, a través de Legio. En la zona occidental del área de servicios, próximo al área de cocina, se localizó un horreum de época altoimperial que cuenta con una cámara de almacenaje apoyada sobre pegollos y que hemos podido estudiar en detalle recientemente (Fernández Ochoa et alii 2013).

En el territorio económico de la Colonia Norba Caesarina, se construyeron diversas villae, entre las que

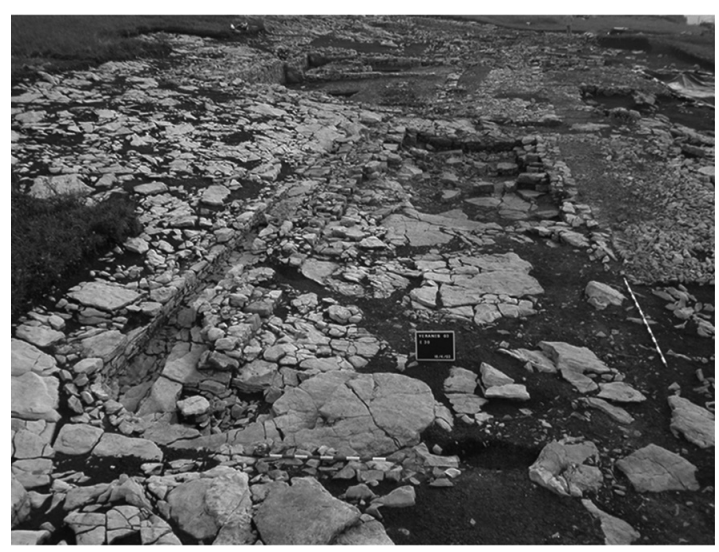

Figura 2. Horreum de la villa romana de Veranes (Gijón). Imagen: Fernández Ochoa y Gil Sendino. 
destaca Monroy/Los Términos (Cerrillo et alii 1988: 174-175, fig. 10; Cerrillo 2006). Alejado de la pars urbana, se puso al descubierto un enorme horreum de época altoimperial que, a tenor de los estudios in situ que he podido realizar, contaba con dos entradas que comunican con dos ámbitos diferenciados: una antesala y una cámara de almacenamiento apoyada sobre ocho muros (Salido 2011b: 135) (Fig. 3).

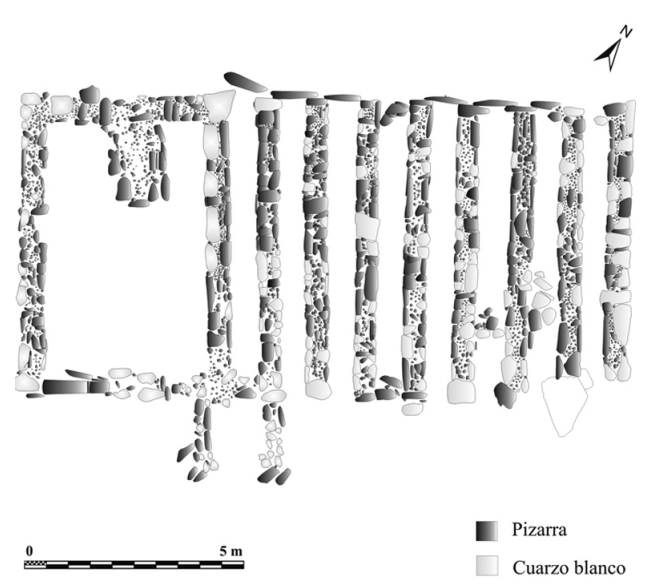

Figura 3. Planta del horreum de la villa romana de Monroy (Cáceres).

Próximo a Olissipo, la antigua Lisboa, de la que dista unos $20 \mathrm{~km}$, se puso al descubierto el horreum del asentamiento de Freiria (Cardoso y Encarnação 1992-1993: fig. 4). La existencia de calles que organizan el plan urbanístico de este asentamiento rural y las grandes dimensiones del granero construido, dotado de una cámara de almacenaje que mide aproximadamente $12 \mathrm{~m}$ de longitud y $8 \mathrm{~m}$ de anchura, nos permite plantear la hipótesis de que nos encontramos ante un enclave rural de mayor entidad, que se asemeja a los vici rurales. Es importante destacar que la interrelación socioeconómica que existía entre los vici y las villae fue tan intensa que el propio Varrón describe el vicus como el lugar de aprovisionamiento y venta de excedentes de la villa (Var. $R .1,16,4,4)$. Por otro lado, Frontino sitúa el vicus in modum munitionum, es decir, en las proximidades de las villae (De Conditionibus Agrorum, 53, 1-15) (Martínez 2006: 117-122). La entidad del asentamiento explicaría que el horreum construido sea el más grande documentado hasta el momento en Hispania.

También en la Lusitania las recientes excavaciones arqueológicas realizadas a partir de la construcción de la Autovía de la Plata han puesto al descubierto varios horrea rurales, como el granero de la finca de "Royanejos", situado a unos $6 \mathrm{~km}$ al norte de Augusta Emerita, que cuenta con una cámara de almacenaje sustentada sobre seis muretes paralelos (Olmedo y Vargas 2004: 37, figs. 23 y 27). En el municipio de Cañaveral (Cáceres), se puso al descubierto otro horreum que cuenta con dos ámbitos separados: una antesala amplia al norte y una cámara de almacenaje de grano apoyada sobre varios muros (Vargas y Matesanz 2006: 121-122, figs. 1 y 2). Las excavaciones arqueológicas de urgencia realizadas en el municipio de Carrascalejo (Cáceres) pusieron al descubierto otro horreum que debió formar parte de la pars rustica de una villa romana de época altoimperial, fechada a principios del siglo I d.C. (Drake 2006: 225, fig. 1).

En la pars fructuaria de la villa de Doña María (Badajoz), entre la segunda mitad del siglo I d.C. e inicios del siglo II, se construyó un granero a aproximadamente $400 \mathrm{~m}$ al norte de la pars urbana (Aguilar y Guichard 1993: 110-111, fig. 34). Se trata de un edificio que contaba con un suelo de pizarra apoyado sobre tres muros paralelos. En la villa romana de São Cucufate, durante el primer tercio del siglo II d.C. (fase II), se construyó un horreum dividido en seis espacios que servían de almacén de grano (Etienne 1990: lámina L, no 1-6). El pavimento descansaba directamente sobre los muros internos del edificio y las banquetas situadas junto a los muros perimetrales. También contaban los muros con aberturas y una cámara de aireación en la parte inferior, sostenida por arcos de ladrillo, que permitía ventilar el espacio de almacenaje.

En el establecimiento rural de Torre de Palma (Portalegre, Portugal), a mediados del siglo II d.C., se edificó una construcción rústica que contaba con un espacio utilizado como granero (Maloney y Hale 1996: 282, fig. 4). Está definido por la existencia de tres muros paralelos en su interior. En cambio, nos resulta difícil aceptar la hipótesis propuesta por Maloney y Hale, quienes plantean que otra construcción denominada granero sur constituyese otro almacén de cereal (1996: 281, fig. 4). El tipo de construcción y planta del edificio no nos ofrece suficiente información para determinar su funcionalidad.

Recientemente se ha dado a conocer un horreum apoyado sobre muros paralelos en la villa romana del Vale do Mouro (Coriscada, Mêda, Portugal) ${ }^{7}$, del que apenas tenemos información. De cronología dudosa es el horreum del establecimiento rural romano de Fonte do Sapo (Santarém, Portugal), dotado de tabulatum apoyado sobre varios muros paralelos (Moutoso 2006: 45, 219-220, fig. 15).

\footnotetext{
${ }^{7}$ Los primeros resultados se han presentado parcialmente en el Congreso de la SECAH celebrado en Braga (abril, 2013).
} 
En la Lusitania se han localizado también graneros construidos durante la fase bajoimperial. Así se constata en la villa romana de São Cucufate (Beja, Portugal), donde cinco muros paralelos servían de base de un tabulatum sobre el que se almacenaba el grano y otros productos (Etienne 1990: lámina L, nº 22). En la segunda mitad de este mismo siglo, se construyó en la zona rústica de la villa romana el granero de La Sevillana en Esparragosa de Lares (Badajoz) (Aguilar y Guichard 1993: 123, fig. 43).

La escasa distancia entre estos establecimientos rurales y el caput civitatis, que varía de entre 5 y $20 \mathrm{~km}$, nos indica que la interrelación económica entre ambos sería muy estrecha. Un dato que nos podría aproximar a su estudio es el cálculo teórico de la capacidad de almacenaje de los horrea sobreelevados, un cómputo que siempre debemos considerar impreciso, dudoso y muy posiblemente inexacto. El primer problema que nos encontramos es que los horrea son edificios que conservaban en su interior no sólo el cereal, sino también otros productos alimentarios perecederos que se guardaban separadamente; además, era necesario habilitar espacios para el paso del personal encargado de los almacenes. Por otro lado, debemos tener en cuenta que, aunque el granero se construyó con unas dimensiones determinadas, pudo no hallarse repleto en ningún momento durante el periodo de uso; también pudo ser continuamente llenado y vaciado, según la estación del año. Otro problema a considerar es el propio modo en que se almacena el cereal, bien en sacos, a granel o en arcones de madera, lo que nos impide determinar con exactitud el volumen que podía acoger en su interior. Tampoco conocemos la anchura de los tabulata, un dato importante a tener en cuenta para calcular la capacidad de resistencia del pavimento para sostener la carga almacenada, que podría dañar seriamente la infraestructura del horreum, especialmente en aquellos dotados de sobrados de madera. También es importante reseñar que, en el caso hispano no se han realizado análisis arqueobotánicos de muestras recogidas durante la excavación que nos permita determinar cómo y qué productos se conservaron en el interior de estos almacenes y testimoniar la infestación del grano almacenado.

En función de estos condicionantes y a la espera de poder contar con más datos, resulta difícil plantear una capacidad de almacenaje máxima de los horrea hispanorromanos. No obstante, aunque no podamos ofrecer una estimación cuantitativa del almacenamiento de los graneros, es cierto que la simple comparación de las dimensiones de los horrea rurales hispanorromanos con la de los graneros descubiertos en otras provincias septentrionales del Imperio ${ }^{8}$, nos permite

\footnotetext{
${ }^{8}$ En el limes renano-danubiano, en el último cuarto del siglo II d.C. el grano necesario para aprovisionar a las tropas
}

suponer que en los establecimientos rurales hispanos no se acumulaba todo el cereal producido en los fundi de las villae o la extensión de la hacienda era menor en el caso hispano. Si pensamos que el interés del dominus sería vender los excedentes agrícolas ${ }^{9}$, más que acumular una producción que podía perderse por diversos factores (humedad, temperatura, insectos, roedores, etc.), sería más conveniente enviar la mayor parte de la cosecha en circulación rumbo a las ciudades o a los mercados rurales (Gabba 1988: 152), para su posterior venta, almacenaje en otros horrea urbanos o para ser transformado en los pistrina (molinerías y panaderías/pastelerías) ${ }^{10}$. La diferencia del tamaño de los horrea dependería, por tanto, no sólo del volumen de cereal que sería posible obtener del territorio económico de la villa, sino también de los intereses personales del dominus, la extensión de la parte destinada al cultivo, puesto que hay que reservar la mejor parte de la cosecha para la siguiente siembra y también para el consumo del personal que vive y trabaja en la villa. Otro dato que hay que tener presente son las condiciones de hambruna de los trabajadores del campo en época romana que nos informa sobre la realidad propia de una economía de subsistencia ${ }^{11}$.

procedía esencialmente del sur, porque las provincias septentrionales donde estaba asentado el ejército no fueron lo suficientemente fértiles para alimentar a los soldados, de modo que fue necesario importarlo de regiones meridionales. En este contexto, debemos poner en relación los grandes horrea de las villae, situados en la zona inmediatamente al sur del limes, con el envío de grano a las tropas asentadas en la zona fronteriza (Salido 2011: 259, nota 216). La capacidad de almacenaje de estos graneros supera notablemente el volumen de cereal que eran capaz de conservar los graneros rurales hispanorromanos.

${ }^{9}$ Catón recomienda al agricultor orientar su producción al mercado para obtener así una mayor rentabilidad económica de su trabajo $(A g r .2,7,4)$. Nos informa también de que el cultivo de cereal dejó de ser rentable para los propietarios que preferían cultivar viñedos y sobre todo olivares. De hecho, la contabilidad de las fincas registraba solamente las entradas y la forma de utilización de los cereales; en cambio, cuando se trata del vino y del aceite se anotan las ventas, el cobro del precio de la venta, los créditos incumplidos y las provisiones disponibles para su comercialización.

${ }^{10}$ Recientemente hemos realizado un trabajo que analiza el estado de la cuestión de las panaderías y pastelerías, así como de las molinerías, descubiertas en Hispania en los últimos años (Bustamante et alii 2012).

${ }^{11}$ Estas pésimas condiciones del campesinado romano quedan reflejadas en varios textos de época altoimperial. Galeno relata su propia experiencia con la alimentación del campesinado: "una vez cuando yo era joven, me lancé a la aventura yendo al campo con dos amigos de mi misma edad y nos encontramos entre un grupo de campesinos que acababan de comer. Las mujeres estaban a punto de hacer pan, ya que ellos no lo tienen, y una de ellas echó algo de trigo en un recipiente para que se cociese. Le echó la sal y nos lo ofreció. Nosotros aceptamos, ya que habíamos caminado mucho y estábamos hambrientos. Comimos mucho, pero inmediatamente después sentimos una pesadez de estómago insoportable, como si hubiéramos comido barro. Al día siguiente teníamos una indigestión monumental, de forma que no podíamos comer 


\section{EL ALMACENAJE Y REDISTRIBUCIÓN DEL GRANO EN EL ÁMBITO URBANO: TESTIMO- NIOS ARQUEOLÓGICOS}

En el estudio del abastecimiento de cereal en las ciudades hispanorromanas, nos encontramos con el problema de determinar los espacios y edificios que debieron servir para almacenar y redistribuir el grano enviado. La ausencia de estudios concretos sobre horrea, así como el desinterés por este tipo de estructuras, ha supuesto hasta el momento el desconocimiento generalizado de las técnicas constructivas, tipología y procedimiento para el almacenaje del cereal de época romana. Como resultado de ello, se tiene conocimiento de muy pocos horrea urbanos en Hispania, especialmente de época bajoimperial, y todavía encontramos muchas dificultades para interpretar correctamente los edificios descubiertos. Existe una tendencia general a denominar granero a cualquier edificio que podía cumplir la función de almacén, pero ya hemos defendido en trabajos anteriores (Salido 2003-04; 2008; 2011), que estos edificios requerían de unas técnicas constructivas especiales para la óptima conservación del grano. En numerosas ocasiones, son interpretados como graneros edificios que posiblemente no sirvieron para el almacenaje del cereal y, sin embargo, a partir de su descubrimiento y dimensiones, se plantean estudios de capacidad y abastecimiento de grano y la fiscalidad del territorio rural de la ciudad ${ }^{12}$. Es necesario en este sentido tratar de diferenciar los graneros de los almacenes genéricos, aunque el término latino horreum comprenda ambos tipos. Otra cuestión importante a tener en cuenta es la dificultad para determinar la titularidad estatal o privada de dichos horrea. En la bibliografía, se suelen interpretar como públicos todos aquellos edificios aparecidos en ámbito urbano, de grandes dimensiones, mientras que la epigrafía y la documentación escrita nos informan sobre la titularidad y gestión de numerosos horrea privados y públicos (Dubouloz 2008; Tran 2008). Un último problema que

nada más... Pregunté a los del lugar qué sentían ellos cuando comían este trigo cocido y me contestaron que lo comían con frecuencia y que efectivamente era indigesto y pesado..." (Galeno, Corpus Medicorum Graecorum, 5, 4, 2, 227; traducción al español en Arce 2006: 14).

12 Algunos almacenes descubiertos pudieron servir como almacenes temporales de grano guardado en sacos, pero las técnicas empleadas en su construcción no permiten interpretarlos a priori como graneros con pavimentos sobreelevados. Este podría ser el caso del horreum de la villa romana de Cal.lípolis en el ager Tarraconensis (Prevosti 2011: 436-437), donde se han testimoniado apoyos colocados a una distancia lo suficientemente grande como para no poder soportar el peso del cereal almacenado, en caso de que no contara con más soportes. Ante los datos que disponemos, podríamos pensar que se trata de un almacén de otro tipo de productos. podemos destacar es la ausencia de análisis arqueobotánicos que nos ofrecen información muy valiosa sobre el tipo de cereal conservado, el tiempo y el sistema de almacenaje (a granel, en sacos, etc.) y los lugares de producción y el radio de abastecimiento de determinadas especies de grano.

La mayor parte del cereal y de los demás productos agrícolas obtenidos en los territorios económicos de las ciudades eran comercializados en los mercados rurales, a veces incluso promovidos en las propiedades de los grandes terratenientes para dar salida a su producción ahorrando costes de transporte (Gabba 1988: 152-153; Chaouali 2005), así como en los macella (De Ruyt 1983; Torrecilla 2007), en las tabernae y otros espacios comerciales distribuidos por la ciudad ${ }^{13} \mathrm{y}$ mediante intermediarios en las nundinae o ferias semanales ${ }^{14}$. Por tanto, la comercialización de los productos agrícolas, sujeta a gravámenes fiscales ${ }^{15}$, supuso un continuo aprovisionamiento de alimentos a la población, de ahí que incluso los macella sean denominados como "mercado de provisiones" en referencia a que los plebeyos obtienen de allí sus suministros ${ }^{16}$. Este continuo mercadeo evitó, sobre todo durante el periodo republicano, almacenar en grandes horrea urbanos las ingentes provisiones que requería la población y, por tanto, debemos concebir estos edificios no como almacenes de los suministros consumidos diariamente, sino como lugares de almacenaje temporal y de redistribución con fines determinados. A diferencia de lo que se ha defendido hasta el momento, muchos horrea debieron ser de titularidad privada, destinados a la redistribución de productos temporales que requerían ser comercializados a corto plazo para evitar su pérdida. Algunos servirían como almacenes de los productos que serían posteriormente vendidos por los comerciantes, quienes previamente habían alquilado a sus propietarios los horrea o determinados espacios de almacenaje y cellae dentro de los edificios. Otros almacenes se dedicarían a la venta directa de productos para los comerciantes interesados en revenderlos posteriormente ${ }^{17}$.

Aunque a nivel general desconocemos cómo se administraban o recaudaban la mayoría de los impuestos

\footnotetext{
${ }^{13}$ En el caso hispano la epigrafía no hace mención a la existencia de áreas de actividad económica como en la propia Roma o en el Norte de África, denominadas como area radicaria o area frumentaria (Papi y Martorella 2007: 182-183); pero muy posiblemente debieron reservarse espacios dentro de la ciudad para las actividades diarias relacionadas con el cereal.

${ }^{14}$ Dig. 50, 11, 2: "Si se autoriza a los agricultores o pescadores que llevan sus mercancías a la ciudad para venderlas, se arruina el suministro, pues se aparta de su trabajo a los hombres del campo".

${ }^{15}$ Var. R. 3, 2, 16; Cic. Div. 2, 27; Tiberius 34; Calig., 40, 2; Plin. Nat., 33, 164; Edictum de Pretiis rerum venalium; Hist. Aug. Helvio Pértinax, 7, 5-7.

${ }_{16}$ Plin. Nat. 19, 52: ex horto plebei macellum.

${ }^{17}$ Sobre la multifuncionalidad de los horrea, v. Virlouvet 2011.
} 
en las comunidades romanas y sobre la base de qué principios, tenemos conocimiento de la obligatoriedad de prestar jornadas de trabajo para la comunidad en ciudades como en la antigua Urso (Osuna, Sevilla), tal y como estipuló la Lex coloniae Genetivae, que generaban un volumen enorme de excedentes agrícolas y también sabemos de la asistencia a los pobres de las ciudades por parte de los grandes terratenientes, que consistía en el ofrecimiento de cereales a bajo precio (Melchor 1993: 95-104) y eventualmente también mediante contribuciones en especie (Cic. Verr. 3, 2). Esta necesaria acumulación de excedentes obligó a la construcción de numerosos horrea, que desgraciadamente apenas se han podido reconocer en el registro arqueológico. Otro factor que hay que tener en cuenta es que, aunque algunos almacenes fueron de titularidad pública, la gestión quedaría en manos de propietarios y rentistas privados, tal y como nos informa la documentación jurídica y epigráfica (Dubouloz 2008: 277-294).

Los primeros horrea urbanos documentados en Hispania corresponden a la primera fase de expansión y consolidación del poder de Roma en la Península Ibérica y constituyen desde su fundación uno de los edificios imprescindibles para cubrir las necesidades comerciales $\mathrm{y}$, por supuesto, como medio para garantizar el aprovisionamiento alimentario a la población (Fig. 4).

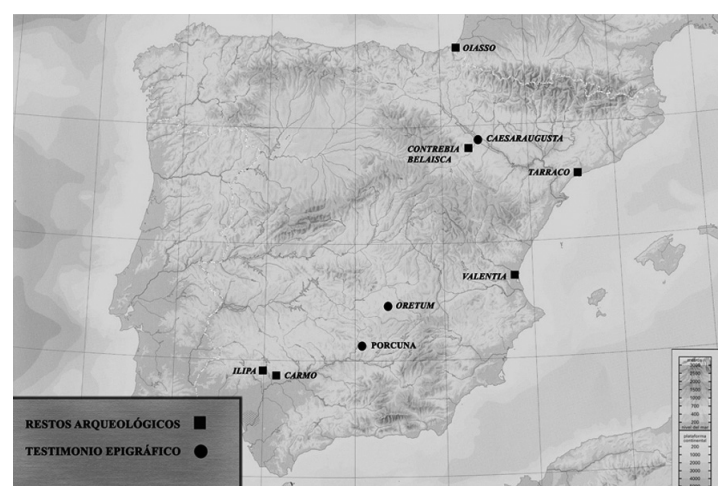

Figura 4. Mapa de dispersión de los horrea de las ciudades hispanorromanas.

El edificio más antiguo documentado que podríamos calificar como horreum por su función exclusiva como almacén de productos se halla en la ciudad celtibérico-romana de Contrebia Belaisca (Botorrita, Zaragoza), debido a la rápida influencia que ejerció sobre la misma el contacto con Roma a través de su conexión con el río Ebro ${ }^{18}$. En la zona meridional del altozano donde se emplazó el asentamiento, denomi-

\footnotetext{
${ }^{18} \mathrm{El}$ mismo influjo que explica la aparición de los primeros macella en ciudades como Celsa (Torrecilla 2007: 19).
}

nado como "Cabezo de las Minas”, se construyó un gran edificio de adobe en torno al siglo II a.C. que preludia el tipo constructivo de los almacenes genéricos romanos ${ }^{19}$. Esta enorme construcción, de 15 x 15 $\mathrm{m}$, consta de cinco estancias estrechas y alargadas. En planta es similar al horreum de la ciudad norteafricana de Djemila (Papi y Martorella 2007: 178-180), pero a diferencia de éste, no cuenta con los sistemas de sobreelevación del suelo que permitiría conservar el cereal a largo plazo en su interior. Los mechinales documentados en las caras internas de las paredes, a una altura de $3 \mathrm{~m}$, nos informan sobre la construcción de una segunda planta, pero indudablemente no corresponden a los vanos de encaje de los soportes del suelo. Por tanto, nos hallamos ante un almacén simple dotado de cinco cellae y un espacio porticado que evita, además de las inclemencias del tiempo, los cambios bruscos de temperatura y humedad para conservar en perfectas condiciones las provisiones de la ciudad ${ }^{20}$; protección que requería también el amparo de la divinidad tutelar del almacén que se conservaba en su interior (Salido 2012: 321).

La excepcionalidad de las provincias hispanas donde se han documentado horrea de época republicana nos permite comprender la ubicación de dichos almacenes en las zonas más céntricas del núcleo urbano, a diferencia del patrón que se seguirá en época altoimperial, próximos a las puertas y zonas portuarias de las ciudades.

Un edificio similar en planta se descubrió en el foro de Valentia, fechado en torno al año 100 a.C. (v., entre otros, Ribera 2011). Al igual que el anterior, contaba con cuatro cellae dotadas de un pórtico que cierra el complejo en su extremo meridional. Las cámaras de almacenaje fueron construidas con muros de opus quadratum en los que se conservaron dos y tres hiladas, correspondiendo las primeras a la cimentación del edificio; por encima de este primer nivel, se halló el pavimento que se encontraba a la misma altura que la calle, por tanto, no hay duda de que no se trata de un suelo sobreelevado, técnica constructiva típica de los graneros romanos. Este dato es un argumento de peso para que no podamos comparar ni en planta ni

\footnotetext{
${ }^{19}$ La interpretación del edificio ha sido ampliamente debatida en la historiografía. Algunos autores lo han identificado como una curia o lugar de gobierno; también se ha interpretado como un templo, en el que cada una de las cinco compartimentaciones estaría dedicada a una divinidad. Manuel Medrano lo consideró un mercado, dada su cercanía con las tenerías excavadas en el yacimiento (Medrano et alii 1991) y solamente A. y M. Beltrán llegaron a plantear que efectivamente se trataba de un almacén (Beltrán y Beltrán 1989: 356).

${ }^{20}$ Se trataría de productos perecederos que, dadas las técnicas empleadas en la construcción del edificio, solamente podrían conservarse durante un breve plazo de tiempo.
} 
en función el horreum de la Almoina de Valencia con los graneros militares numantinos ${ }^{21}$. Nos encontramos, por tanto, ante un almacén genérico que serviría para custodiar los productos destinados a aprovisionar a la ciudad. Respecto a su titularidad, el hecho de que se encuentre en el centro de la ciudad, en pleno foro, no es un argumento de peso para defender su carácter público, pues ni su monumentalidad ni sus grandes dimensiones son rasgos exclusivos de horrea públicos, máxime si lo comparamos con los enormes almacenes republicanos de Roma pertenecientes a las grandes familias aristocráticas que mandaron construir estos edificios para su propio uso y beneficio (Rickman 1971: 163-170) (Fig. 5).

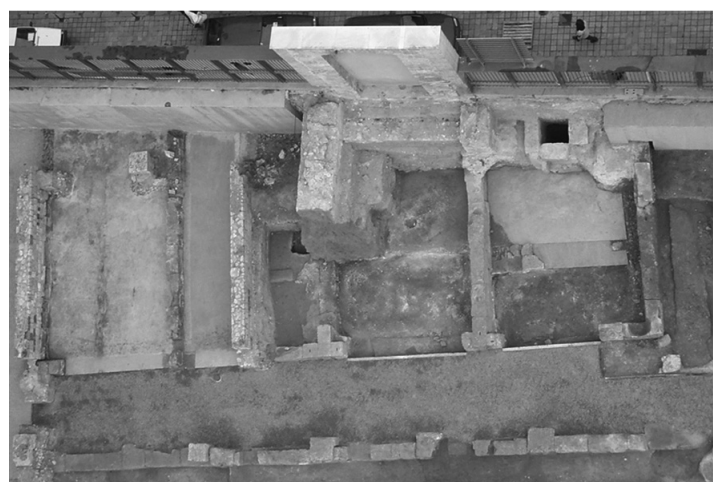

Figura 5. Vista aérea del horreum de la ciudad de Valentia. Imagen: Archivo SIAM, Valencia, extraída de Escrivá, I., Ribera., A. y Vioque, J. (2010): Guía del Centro Arqueológico de l'Almoina, Valencia, 45.

A tenor de los restos de almacenes de época republicana, podemos concluir que las ciudades en este periodo no debieron contar con grandes reservas de grano, lo que debió suponer crisis alimentarias en tiempos de malas cosechas. Los horrea en este periodo sirvieron muy posiblemente como espacios de conservación a corto y medio plazo, muy prácticos para una economía de subsistencia y continuo mercadeo que consumía los productos perecederos inmediatamente después de ser enviados desde las zonas de producción. Por tanto, al igual que sucede con los magazzini repubblicani de Os-

\footnotetext{
${ }^{21}$ Ribera considera que "los edificios militares numantinos se parecen en planta, datación y seguramente en función con el de la Almoina", sin embargo, los estudios que hemos podido llevar a cabo sobre las excavaciones arqueológicas dirigidas por A. Schulten nos permiten determinar que los muros divisorios de los horrea numantinos no diferencian las cellae del almacén, sino que sirven como soportes del pavimento, de modo que la funcionalidad del edificio es distinta (Salido 2009: 684-686). La disposición de los muros internos, situados a una distancia máxima de $3 \mathrm{~m}$ (que permiten sostener el peso del cereal y otros productos conservados) y su altura nos permite suponer su uso como soportes del tabulatum.
}

tia, estos horrea pudieron servir también como espacios comerciales de variada funcionalidad que implicaban la compra-venta de productos, el alquiler de espacios de almacenaje para su venta al por mayor, etc.

En época altoimperial, las ciudades se fueron dotando de mecanismos administrativos capaces de suministrar el cereal necesario para la población y obtener fondos para mantenerlo a un precio asequible por la plebe, incluso organizando legaciones encargadas de aprovisionar a la ciudad en momento de dificultades de abastecimiento ${ }^{22}$. Son continuas las referencias a las épocas de escasez de grano y otros alimentos en las fuentes clásicas, pero llaman la atención los resultados negativos que podían causar las medidas políticas como el abaratamiento de los cereales que supusieron en más de una ocasión el aumento de la escasez de grano $^{23}$. La respuesta a este fenómeno debemos buscarla en la contracción de la economía derivada de la respuesta de los comerciantes privados que, buscando un mayor interés en la venta del cereal, deciden esperar el momento para vender su stock cuando de nuevo el grano alcanza un precio elevado a medida que aumenta su necesidad. La connivencia de los ediles, encargados de la cura annonae en la fase altoimperial (Babled 1892; Lex Irnitana, cap. XIX, Dig. 16, 2, 17; Pérez 2011: 230-234), con los panaderos y mercaderes agravaría aún más esta situación de penuria entre la plebe ${ }^{24}$.

Para evitar el fraude, la Lex Irnitana señala explícitamente que los ediles tienen derecho y capacidad de ocuparse del abastecimiento de trigo (annona) y de controlar los pesos y medidas (pondera mensurasue), reconociéndoseles la potestad de señalar una multa (multam dicendi) y aplicar una sanción a los municipes o incolae con un límite de $5.000 \mathrm{HS}$, con el fin de evitar el alza de precios (Irn. 19). La reciente aparición de un epígrafe en el término municipal de Utrera (Sevilla), fechada entre el siglo II o comienzos del III d.C., confirma también la aplicación de multas a los pistores por parte de los duouiri, posiblemente porque la pena impuesta supera la cantidad aplicada por los ediles (Ordóñez y Saquete 2009: 204) ${ }^{25}$.

\footnotetext{
${ }^{22}$ En Tarragona se puso al descubierto entre 1927 y 1929 la inscripción RIT 364 que homenajea a un miembro del ordo que dirigió una legación encargada de proveer de grano a la ciudad (Melchor 1992: 204).

${ }^{23}$ Son numerosas las referencias a esta práctica, como la que se produjo, por ejemplo, en época de Cómodo (Hist. Aug. 7, 14, 2)

${ }^{24}$ Textos que hacen referencia a momentos distendidos, como el Satiricón de Petronio, reflejan los males que tenía que padecer la población, como la queja de Ganimedes durante el banquete celebrado en la casa de Trimalción que se lamenta en los siguientes términos:”¡Malditos sean los ediles que están compinchados con los panaderos!" (Petr. 44). Otras referencias sobre la mala praxis de los ediles es mencionada en Cic. Sest. 95, 114 y 118; Lucil, 48; Suet. Iul. 9; Suet. Dom. 8; V. Max. 6, 6, ext. 5.

${ }^{25}$ El epígrafe dice explícitamente: $Q$ (uintus) L(---) Optat/
} 
Estos envíos y acopios de grano requirieron la construcción de horrea tanto en las ciudades como en las zonas portuarias. En el caso hispano, disponemos de información sobre los almacenes altoimperiales que se hallan en su mayoría en los puertos de las ciudades, salvo el documentado en la antigua Carmo (Carmona, Sevilla). Este edificio, fechado a mediados del siglo I d.C., se construyó cerca de una de las puertas principales de la ciudad (Sedía), en una zona que facilitaba el transporte y comercio de productos (Román 2001). Se trata de un horreum de unos $34 \mathrm{~m}^{2}$ construido con enormes sillares de 0,70 $\mathrm{m}$ de lado alineados en cinco hileras. Estos bloques servían de soporte de un tabulatum o sobrado de madera constituido por numerosas vigas, algunas de ellas encajadas en las caras internas de los muros y también en algunos sillares colocados a una segunda altura que contaban con mechinales. Este sistema constructivo permitía aislar de la humedad el cereal y otros productos perecederos y mantenerlos en unas condiciones óptimas de conservación para su almacenaje a medio y largo plazo (Figs. 6 y 7).

\section{$\overline{\text { us et } Q \text { (uintus) }} C(---)$ Op/tatus IIuir[i]/ ex multis/ pistorum/} posuerunt.
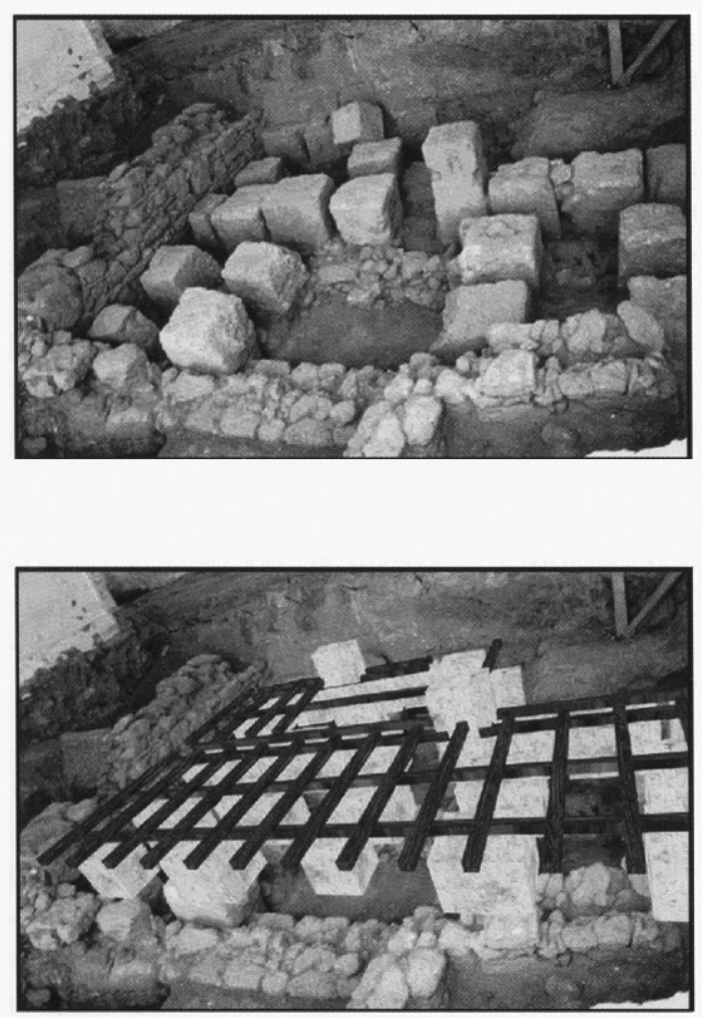

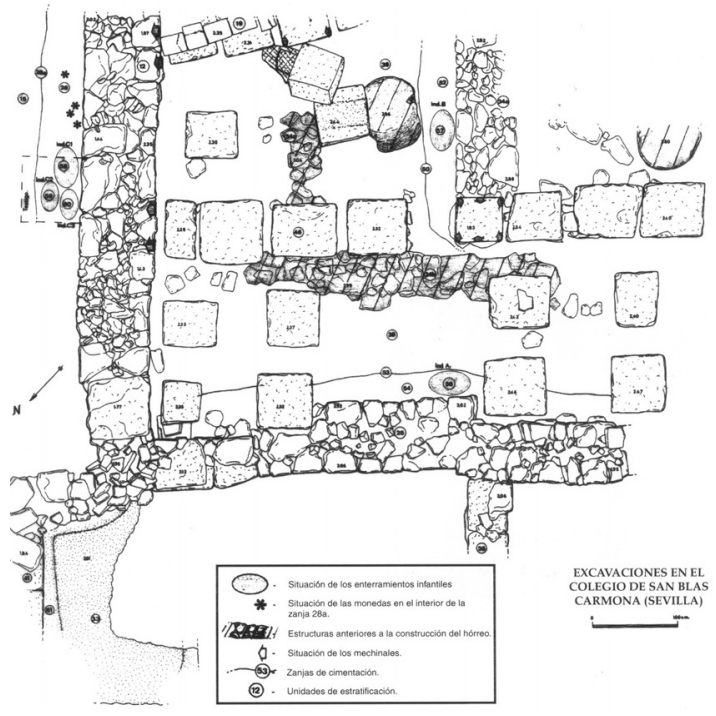

Figura 6. Planta del horreum de la ciudad romana de Carmo (Sevilla). Imagen: Román 2001: fig. 4.

Este tipo constructivo que supone la colocación del pavimento sobre pequeños apoyos de piedra como soportes del pavimento resulta poco eficaz, porque
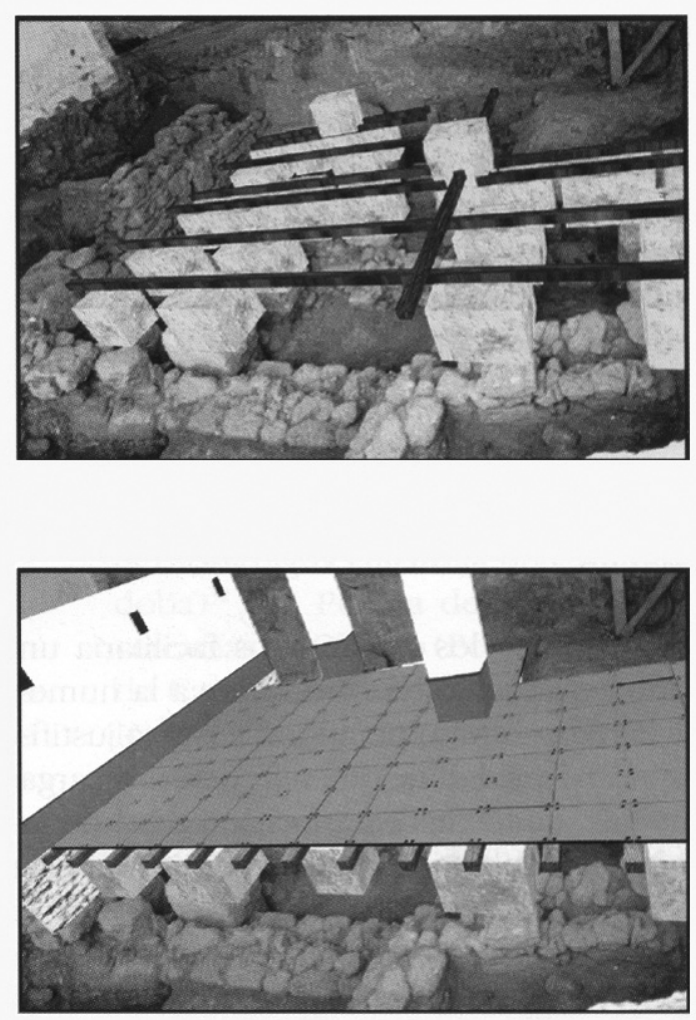

Figura 7. Reconstrucción del tabulatum del horreum de la ciudad romana de Carmo (Sevilla). Imagen: Román 2001: fig. 8. 
requiere de la colocación de numerosos pilares de la misma altura y resulta difícil situar el pavimento de manera horizontal perfectamente equilibrado. Esta inestabilidad y dificultad para colocar el tabulatum o pavimento explica que este sea el tipo de soporte menos usado en época romana, puesto que requiere de la presencia de otros apoyos, como la existencia de mechinales, muros de piedra, dobles muros, banquetas, etc. (Salido 2011: 86). En cambio, la construcción de muros de piedra ofrece una mayor estabilidad y firmeza al pavimento. En ámbito militar se ha fechado el empleo y generalización de este tipo constructivo también en época flavia, momento en que se lleva a cabo una política de estabilización de las fronteras (Salido 2011: 257).

Un edificio similar en cuanto a las técnicas de construcción se ha documentado recientemente en el puerto de Oiasso (Irún, País Vasco), cuya fundación se ha datado entre los años 70 y 120 d.C. (Urteaga, 2003: 202; Urteaga y Alkain 2009: 10). A la espera de que se publiquen nuevas noticias del hallazgo del año 2008 (Alkain 2009-2010), podemos decir que se trata de una construcción de una anchura aproximada de $14 \mathrm{~m}$, que contaba con grandes apoyos de madera, ordenados en dos hileras, de los que se han testimoniado a partir de su impronta al menos ocho.

En la capital de la Tarraconensis, también se identificaron dos enormes horrea de época altoimperial (Adserias et alii 2000: 146). Se trata de dos edificios construidos a finales del siglo I d.C., que debieron cumplir la función de depósito de alimentos y otros productos (Fig. 8).

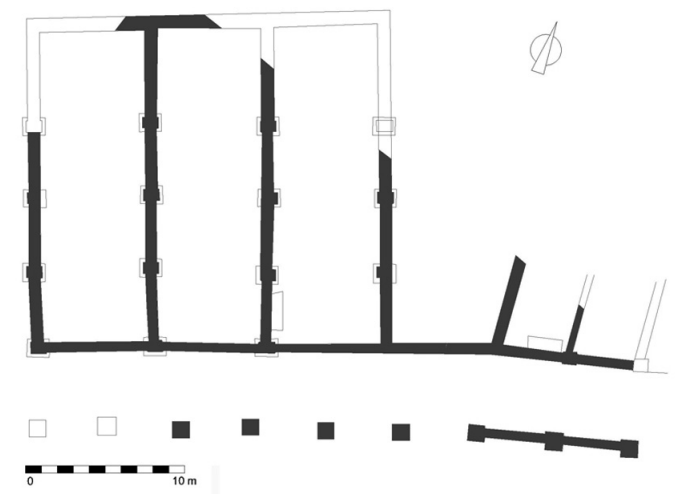

Figura 8. Planta del horreum de la ciudad romana de Tarraco (Tarragona), a partir de Adserias et alii 2000.

El almacén occidental está compartimentado en tres grandes naves de aproximadamente $18,40 \times 6 \mathrm{~m}$ cada una, con una superficie total de unos $110 \mathrm{~m}^{2}$. Las dificultades derivadas de la intervención arqueológica de urgencia y el arrasamiento de los muros impide saber si las caras internas de los tabiques contaban con mechinales donde se encajarían las vigas de un suelo de madera sobreelevado. No obstante, se han documentado tres grandes sillares encastrados en cada una de las fachadas que más que pequeños refuerzos o contrafuertes de las mismas, deberíamos interpretarlos como soportes internos de un posible tabulatum. También los tabiques divisorios de las cámaras de almacenaje contaban con estos tres grandes apoyos que, alineados con los anteriores y situados a la misma altura, servían indudablemente como soportes del pavimento sobreelevado. La superficie interior realizada a base de guijarros no constituye una preparación previa de un pavimento enlosado, como plantearon sus excavadores, sino que se trata de un pavimento aislante de la humedad del suelo que además facilitaría la limpieza de la parte inferior del tabulatum donde caería el grano y otros productos almacenados en su interior -en mayor cantidad si se vertía a granel-. Ambos edificios contaron en una fase posterior con una entrada monumental porticada orientada directamente hacia el área portuaria de la ciudad. El nivel de derrumbe se ha fechado en torno al siglo III d.C. Las técnicas constructivas y la planta son muy similares a las de los graneros excavados en el yacimiento norteafricano de Thamusida (Papi y Martorella 2007).

Las técnicas empleadas en la construcción de los horrea altoimperiales hispanos, a diferencia de los de época republicana, nos indican que muy posiblemente debieron servir para contener el cereal y los otros productos alimenticios que serían repartidos y/o comercializados asiduamente, pero también -y esto es lo importante- acumulados a medio y largo plazo. Así pues, la función de algunos de estos horrea fue servir de reservas estratégicas destinadas a contener productos perecederos, que se venderían a bajo coste en periodos de carestía para reducir el precio de los productos de primera necesidad (entre los que destaca el grano), lo que requeriría la construcción de pavimentos sobreelevados y/o la continua remoción y limpieza del cereal y demás productos efímeros almacenados en su interior. Además de estos almacenes, debían existir otros dedicados a conservar a corto plazo el cereal que era puesto a la venta poco después de ser recibido en la ciudad, lo que no precisaba la construcción de suelos sobreelevados. Horrea de este tipo debieron ser frecuentemente construidos en las ciudades hispanorromanas, pero apenas se han puesto al descubierto hasta el momento; un ejemplo reciente se ha localizado también en la antigua ciudad de Ilipa, muy próximo al puerto fluvial (Rodríguez Gutiérrez 2007: 178). También hay que tener en cuenta que las unidades domésticas contaban con sus propias reservas 
y almacenes sobreelevados, que permitían conservar el cereal necesario para el sustento alimenticio familiar ${ }^{26}$.

\section{LA GESTIÓN Y LA ADMINISTRACIÓN DEL GRA- NO EN EL ÁMBITO URBANO: TESTIMONIOS EPIGRÁFICOS}

Aunque los restos arqueológicos nos informan sobre la construcción de enormes graneros que debieron acoger el producto de la annona, es cierto que resulta difícil diferenciar los graneros pertenecientes a la comunidad de los construidos por agentes privados. En este sentido, los documentos epigráficos son una fuente determinante para comprender mejor el sistema de gestión de los almacenes y de la administración del grano, una cuestión de primer orden dentro del funcionamiento de la ciudad ${ }^{27}$.

La epigrafía nos informa del envío de frumentum mancipalis, es decir, el impuesto en especie recaudado, controlado y dirigido por la administración imperial ${ }^{28}$. La dedicación aparecida en la antigua Hispalis nos informa sobre la presencia de un liberto imperial que cumplía la función de dispensator del grano estatal ${ }^{29}$ que muy posiblemente se almacenaría en los graneros de la ciudad que aún no se han localizado ${ }^{30}$.

El aprovisionamiento de las ciudades no requirió solo de la participación del Estado, sino que tanto la gestión de algunos horrea como el transporte y compraventa del cereal precisó de la actuación de agentes comerciales privados. A mediados del siglo II d.C.,

\footnotetext{
${ }^{26}$ Los estudios realizados en Pompeya y Herculano nos informan sobre la presencia de reservas temporales de alimentos perecederos como el grano en el interior de las casas, aunque el volumen de las vituallas es indicativo de su consumo continuado y de carácter doméstico (Monteix 2008).

27 "Entre las cosas convenientes para las ciudades, las más importantes es una buena legislación; entre las necesarias, la abundancia de recursos" (Plu. Cuestiones romanas, 41 ).

${ }^{28}$ Cicerón (Dom. 10, 25) expresa su malestar a quien le ha confiado la función de aprovisionar a la ciudad de Roma (omne frumentum privatum et publicum), la recaudación y compra del trigo (provincias frumentarias), su transporte (mancipes) y el almacenaje del grano en los horrea, de modo que muy posiblemente los mancipes se encargarían de su transporte a la Urbs (Alzon 1964: 34).

${ }_{29}$ Aeliae Italiae / uxori sanctis/simae et castis/simae fecit pius / Aug(usti) n(ostri) verna / dispensator / [frumen]t(i) mancip(alis) (CIL II, 1197).

${ }^{30}$ Los restos materiales aparecidos hasta el momento en Sevilla no parecen corresponder a grandes horrea civiles. Solamente el edificio de la Calle Francos podría contener el cereal administrado por el Estado, pero según las últimas investigaciones podría ser el espacio de almacenaje del aceite bético exportado a Roma (Ordóñez y González 2011: 173). No obstante, a tenor de los datos arqueológicos aparecidos, no parece que podamos confirmar que dicha construcción responde al modelo típico de horrea en torno a patio, que contaba con cellae organizados respecto a este patio central, que por el momento no se han podido evidenciar en dicho edificio.
}

entre los años 161 y 169 d.C., durante los gobiernos de Marco Aurelio Lucio Vero, los scapharii o barqueros fluviales de Hispalis mandan colocar una dedicación al Procurador Augg. ad ripam Baetis y delegado local del praefectus annonae (adiutor), también atestiguado en Mactar (CIL VIII, 11796), cuyas funciones son controlar la annona de aceite hispano y africano y dirigir el transporte de otros productos anonarios (solamina transferenda $)^{31}$. En esta última, no se menciona explícitamente el grano como producto de la annona, aunque algunos autores consideran que bajo la expresión solamina transferenda se encuentra el envío de cereal

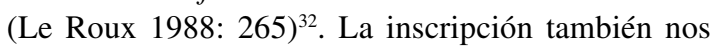
informa sobre la compensación a las corporaciones de navicularii por los servicios prestados en el transporte de las vituallas ${ }^{33}$, mercantes que mantenían un constante tráfico comercial marítimo con Roma ${ }^{34}$.

Otro aspecto importante a tener en cuenta es la colaboración de los miembros de las familias más acomodadas en el abastecimiento de las ciudades. Con el fin de ganarse el favor de sus conciudadanos, para obtener contrapartidas de tipo económico o político o simplemente por compromiso ciudadano, contribuyeron notablemente en el aprovisionamiento de alimentos en época de necesidad (annona cara o gravissima annona) (Rodríguez Neila 1975, 1989; Dardaine y Pavis D’Escurac 1986; Melchor 1992:

\footnotetext{
31 Sex(to) Iulio Sex(ti) f(ilio) Quir(ina) Possessori / praef(ecto) coh(ortis) III Gallor(um) praeposito nume/ri Syror(um) sagittarior(um) item alae primae Hispa/norum curatori civitatis Romulensium Mal/vensium tribuno mi[1(iti) leg(ionis)] XII Fulminat[ae] / curatori coloniae Arcensium adlecto / in decurias ab Optimis Maximisque / Imp(eratoribus) Antonino et Vero Augg(ustis) adiu/tori Ulpii Saturnini praef(ecto) annon(um) / ad oleum Afrum et Hispanum recen/ sendum item solamina transfe/renda item vecturas navicula/ riis exsolvendas proc(uratori) Augg(ustorum) ad / ripam Baetis Scapharii Hispalen/ses ob innocentiam iustitiam/que eius singularem (CIL II, 1180).

${ }^{32}$ Para esta cuestión, véase también Remesal 1986: 101-102.

${ }_{33}$ Son bien conocidos en este sentido los esfuerzos de los emperadores por conceder privilegios a los negotiatores o navicularii que trabajasen para el aprovisionamiento de Roma, como el Edicto de Claudio que ofrecía garantías en forma de recompensa en caso de naufragio o pérdidas (Suet. $\mathrm{Cl}$. 18, 3-4 y 19; Gaius, Inst. 1, 32, c; Tac. Ann. 12, 43, 2-4), ampliamente analizado por Rougé 1966; Pomey y Tchernia, 1978: 237-243. El Digesto $(50,5,3 ; 50,6,6,8)$ también nos informa de la inmunidad de cargos municipales a los que contribuyeron a la annona con uno o varios barcos cargaderos de al menos 50.000 modios en época de Adriano.

${ }_{34} \mathrm{Al}$ respecto, el Codex Theodosianus nos informa de la regulación de impuestos que tenían que pagar los comerciantes procedentes de los puertos hispanos a su llegada al Portus (13. 5. 4: Idem a. Helpidio: "Ex quocumque Hispaniae litore portum urbis Romae navicularii navis intraverit, quae onus dumtaxat fiscale subvexerit, eandem sine interpellatione cuiusquam abire praecipimus nec ulli extraordinario oneri deservire, ut facilius iniuncta sibi possit implere obsequia. Dat. VIII id. mart. Thessalonicae Crispo III et Constantino III conss".; 324 mart. 8).
} 
203 y ss.; 1993; Navarro 1997). En una de estas iniciativas, tres collegia rinden homenaje a un duovir que puso fin a la escasez puntual de grano mediante la colocación de una inscripción en la antigua Aeso (Isona, Lérida) $^{35}$. La actuación de estas asociaciones profesionales para el aprovisionamiento de la annona están perfectamente constatadas, con una importante jerarquización (encabezados por magistri, magistri quinquenales y curatores), pero apenas existen noticias sobre los collegia dedicados al préstamo.

El epígrafe de Aeso es excepcional en cuanto a la mención de collegia Kalendarium et Iduaria duo, apelativos de dudosa interpretación. Fita aduce que lo prestado en las calendas se cobraba en los idus, basándose en el comentario de Horacio (Epod. 2, $64)^{36}$, D'Ors los interpreta como collegia funerarios (1953: 382-382), mientras que Lara considera que los miembros de estas asociaciones profesionales tomaban esos plazos para la cancelación de la cuenta de los deudores, debidamente anotados en libros apropiados (1973: 229-231). Ningún estudio realizado sobre la inscripción ha tenido en cuenta que no es la comunidad, en principio la principal beneficiada de la donación, la que practica el homenaje, sino los collegia de prestamistas.

Esta dedicación no nos informa si este acto de evergetismo vendría acompañado de facilidades para la obtención de préstamos, lo que supondría la donación de dinero a un bajo interés en momentos de dificultades económicas. La administración de los fondos para el crédito estaba constituida generalmente por los legados de los notables de la ciudad y confiada a un vilicus kalendarii e incluso a curatores de rango ecuestre (Vat. 187; CIL IX, 1160; CIL IX 1619; CIL X, 146; CIL $\mathrm{X}, 4584$ ), auxiliados por vilici y procuratores. Tal y como nos informa el Digesto, estos curatores podían incluso organizarse en corporaciones creadas con el fin de crear fondos de crédito que permitían prestar dinero a favor del bien público de los ciudadanos (Dig. 50, 8, 12, 5).

Estas prestaciones fueron promovidas por las propias ciudades a partir del siglo I d.C. para impulsar la agricultura y solucionar problemas puntuales como la escasez de alimentos, mediante la creación de fondos de crédito agrario que tomaron el nombre de kalendaria, haciendo referencia al libro de contabilidad utilizado para su administración (Isid. Etym. 1, 44, 1). Los préstamos se establecían para su devolución en

\footnotetext{
${ }^{35}$ L(ucio) Val(erio) L(uci) fil(io) / Gal(eria) Faventino / IIvirali / qui annona / frumentaria / empta plebem / adiuvit et ob a/lia merita eius / collegia Ka/lendarium / et Iduaria duo / civi gratissimo / posuerunt (CIL II 4468).

36 "Omnem relegit idibus pecuniam, quaerit kalendis ponere” (véase Fita 1898: 533-534).
}

plazos mensuales o trimestrales y se solían reembolsar en los idus del mes establecido, de donde procede el calificativo de los otros dos collegia de Aeso ${ }^{37}$.

A pesar de las referencias textuales que nos informan de la concesión de préstamos a bajo interés en periodos de escasez de recursos, esta dedicación no nos informa sobre el evergetismo crediticio, pues está dedicada exclusivamente al duunviro Lucio Valerio, que formaba parte de una familia de grandes terratenientes ${ }^{38}$.

Los evergetas hispanos también dedicaron su fortuna a la edificación o reconstrucción de determinados edificios municipales de carácter económico. En este sentido, podemos destacar la restauración del macellum de Villajoyosa por parte de M. Sempronius Hymnus a finales del siglo II d.C., bien atestiguada por la inscripción que se mandó realizar en una de las mensae lapidae colocadas en el mercado ${ }^{39}$. Más interesante resulta la inscripción aparecida en Porcuna (Jaén $)^{40}$ que informa de la construcción hacia el siglo II d.C. de un horreum y tabernae por parte del curator Baetis sobre el suelo comprado a la ciudad (solo empto ab re publica) ${ }^{41}$. Posiblemente se le concedió a este evergeta el privilegio de comprar terreno público baldío, a cambio de la construcción de un almacén detrás de unas tabernas, cuyo usufructo posiblemente también correspondía a la comunidad. Aunque la mención post horreum ha generado un cierto debate entre los especialistas, debemos decir que la estrecha vinculación entre la actividad comercial de las tabernas con el horreum nos invita a pensar más en una relación espacial que temporal.

\footnotetext{
${ }^{37}$ Las devoluciones se solían realizar en las idus, como nos informa Horacio (Epod. 2; Sat. 1, 6) y el Digesto (46, 3, 89, 2, scaev. 29). Sobre este asunto, véase Giliberti 1984: 5-14.

${ }^{38}$ El epígrafe CIL II, 4125 hace alusión al conflicto de los límites de propiedades entre Valeria Faventina, familiar de Valerius Faventius de Aeso con otros terratenientes, lo que nos informa sobre la amplia posesión de tierras por parte de la gens Valeria (véase Pons 1979). La riqueza del duunvir ha llevado a interpretar que el grano provendría de sus propias reservas (Melchor 1993: 99).

${ }^{39}$ M(arcus) Sempronius Hymnus suo et M(arci) Semproni Reburri / fili(i) sui nomine macellum vetustate conlap/sum sua pecunia restituerunt item/que et mensas lapideas posuerunt (CIL II 3570).

${ }^{40}$ Quintiu]s Q(uinti) f(ilius) $\mathrm{Q}$ (uinti) $\mathrm{n}$ (epos) $\mathrm{Q}$ (uinti) pron(epos) Q(uinti) abn(epos) Gal(eria) Hispan[us / - - -]tus aedil(is) flamen IIvir pontif(ex) municipi P[ontif(iciensis) / - - ]curator Baetis praef(ectus) cohortis PI[- - - / - - - ]rum equitatae comes et adsessor legati ad / [- - - ]s et adsessor proco(n) s(ulis) provinciae Galliae / [Narbon(ensis)] compluribus immunitatibus et beneficiis inter diffvse / [- - p]rincipib(us) honoratus tabernas / [- - - et post horreum solo empto ab re publica d(e) s(ua) p(ecunia) d(ono) d(edit) (CIL II, 2129).

${ }^{41}$ Existe un debate historiográfico sobre el significado de la expresión solo empto. Tradicionalmente se ha considerado que el suelo fue comprado por la ciudad, pero Goffaux planteó una interpretación diferente que supone la construcción de los edificios en terrenos comprados por el evergeta a la ciudad (Goffaux 2003).
} 
Además no tendría sentido subrayar la temporalidad en una acción evergética que se emprende en un momento concreto sobre unos terrenos recién comprados. Esta hipótesis se refuerza si tenemos en cuenta la estrecha relación espacial y funcional entre horrea y tabernae que debieron constituir una propiedad única. De ahí que la dedicatoria mencione explícitamente la ubicación espacial del horreum recalcando que en uno de los extremos de la insula se hallaba el espacio de almacenaje y en la parte posterior el área de comercio. Una estrecha relación espacial la encontramos en códigos que tratan de solucionar los problemas de herencia ante un posible incendio de dos unidades constructivas distintas (tabernas y horreum vinarium), aunque ubicadas en la misma unidad arquitectónica (insula) (Dig. 33, 7, 7) (Dubouloz 2008: 280). Por otro lado, la vinculación entre ambos espacios de almacenaje y comercio debe llamarnos la atención sobre la funcionalidad de dichos horrea que, en este caso, relacionados con la venta en las tabernas, podría servir más bien como almacén de vino (horreum vinarium) (Sen. Ep. 114, 25; Hor. Carm. 3, 28, 7; Dig. 33.7.7), no tanto de cereal, aunque esta es una hipótesis que no podemos confirmar.

La epigrafía hispana también nos informa de la participación de siervos como trabajadores en los horrea, como en Caesaraugusta (Zaragoza), ciudad portuaria de gran importancia económica, dada la navegabilidad del río Ebro en esta zona en época romana ${ }^{42}$. En 1980 apareció la lápida funeraria de Hyacintus $^{43}$, horrearius de Sura ${ }^{44}$ (Fig. 9). El origen griego del difunto nos informa sobre el carácter servil del trabajador que carece de los tria nomina de los hombres libres, condición jurídica muy común entre los horrearii (Dubouloz 2008: 282, nota 25). Aunque la figura del horreario ha sido objeto de discusión en la historiografía más moderna (Alzon 1964; Serrano-Vicente 2006; Dubouloz 2008 y 2011), aún desconocemos con precisión la responsabilidad y las funciones del mismo. En este caso, podría tratarse de un trabajador de los horrea de su propietario, Sura, que pone a disposición de los horrearii almacenes provistos de medios para mantener la seguridad de las mercancías en ellos depositadas (Dig. 19, 2, 56; idem Paulus, de off. praef. vig), lo que nos informaría de la existencia de unos horrea privados en

\footnotetext{
${ }^{42}$ Las últimas investigaciones realizadas en Zaragoza han puesto al descubierto las estructuras del puerto fluvial de la antigua Caesaraugusta (véase Erice 2011).

${ }^{43}$ Se han atestiguado dos inscripciones en Hispania con la mención Hyacinthus en Sagunto (EE IX 379; CIL II2/14, 540; HEp 12, 2002, 506) y en Mérida (Ramírez Sádaba 2003: 364365, no 17; AE 2003, 877; HEp 13, 2003-2004).

${ }^{44}$ El epígrafe apareció en la calle Dr. Galve en el Barrio de Miralbueno que dice textualmente: Hyacintvs/Svrae/horrearivs [h(ic) s(itvs) e(st)] (HEp 25008) (Beltrán 1982: 56).
}

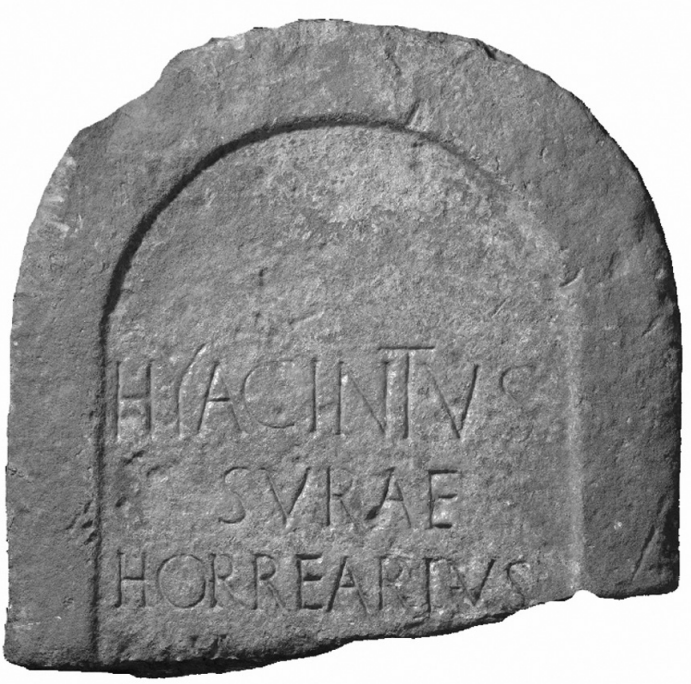

Figura 9. Inscripción del horrearius Hyacinto de la ciudad romana de Caesaraugusta (Zaragoza). Imagen: Fondo fotográfico de Hispania Epigráfica.

la ciudad, o bien se encarga de los trabajos de almacenaje de las mercancías de su dominus Sura en horrea que, bien podrían ser de titularidad estatal o privada, con espacios de almacenaje determinados previamente alquilados. Esta responsabilidad que se le confiere al horrearius sobre la custodia de los bienes conservados es la que motivó los continuos engaños y abusos de siervos, que en connivencia con los ladrones, facilitaban los robos de los almacenes con fuerza en las puertas. Sabemos que esta práctica debió ser muy extendida, al menos en el siglo III d.C., porque el propio Caracalla incluyó en la legislación la posibilidad de tortura contra los esclavos custodios en caso de robo de los almacenes mediante rotura de las cerraduras (Serrano-Vicente 2006: 134-135).

Próximo al decumanus de la misma ciudad, en Zaragoza, se halló otro epígrafe que consiste en la dedicación de un liberto a un genio tutelar de los horrea (CIL II, 2991) ${ }^{45}$. Estos genii fueron venerados como verdaderos dioses porque se esperaba de ellos una protección real (Speidel y Dimitrova-Mileva 1978: 1549-1550) y su imagen pudo ser colocada en las hornacinas de los patios internos de los horrea o en pequeños edículos y espacios sacros construidos para su culto ${ }^{46}$. Se trata de las divinidades protectoras de

\footnotetext{
${ }^{45}$ Se trata de bloque o base de estatua moldurada que está rota por el ángulo superior derecho: Genio Tutelae/Horreorum/ A(uius) Annius/Eucharistus/Ex Voto

${ }^{46}$ La aparición de la única estatuilla de un genius horreorum aparecida hasta el momento -en este caso en ámbito militar- en el campamento de Niederbieber (CIL XIII, 7749) resulta enormemente interesante, porque sus dimensiones y significado nos informan sobre su colocación en un nicho o
} 
los almacenes, el deus in cuius tutela hic locus est (Henzen 1874: 146; Rickman 1971: 312), o como afirma Servio, Genium dicebant antiqui naturalem deum uniuscuiusque loci vel rei vel hominis (Serv. ad Georg, 1, 302). Las dedicaciones a los genii horreorum por parte de libertos y trabajadores de origen servil son frecuentes en la epigrafía (Rickman 1971: 312-315; Salido 2012) y aparecen referidos tanto a horrea privados como públicos ${ }^{47}$. Por ello, la inscripción aparecida en Zaragoza no nos ofrece pistas sobre la titularidad de dichos horrea que, por otro lado, tampoco podemos relacionar con los almacenes donde trabajaría Hyacintus, horreario de Sura. En cambio, esta inscripción votiva nos indica que, a diferencia de lo que sucede con las asociaciones profesionales (corpora, collegia o sodalicia), los trabajadores encargados de los almacenes no parecen organizarse como asociaciones de carácter religioso (Tran 2008: 298-299). En este caso, este trabajador parece llevar a cabo una consagración de manera particular, en cumplimiento de una promesa, para salvaguarda de los almacenes.

\section{HORREA ECCLESIAE: NOTAS SOBRE EL PAPEL DE LA IGLESIA EN LA ADMINISTRACIÓN DE LOS ALIMENTOS}

En época tardorromana se produce una paulatina concentración de las propiedades en manos de la Iglesia. Se conservan algunas referencias literarias tardoantiguas del almacenaje de grano en los horrea ecclesiae (Rickman 1971: 156-157), como en Roma durante el siglo VI. Según Gregorio de Tours, se produjo en el año 590 una inundación del Tíber que destruyó los horrea de la Iglesia y el grano almacenado en su interior. En el año 605 el Papa Sabiniano mandó abrir los graneros eclesiásticos (iussit aperiri horrea ecclesiae) y redistribuir el grano almacenado en su interior entre la población más desfavorecida. Este papel de la Iglesia como benefactora de los pobres mediante el reparto gratuito de grano se manifestó continuamente a lo largo de los siglos y permaneció como uno de los principales cometidos de los obispos que no dudaban en manifestar su generosidad para con

aedicula de los horrea (Salido 2012: 325). Sabemos también por la epigrafía de la colocación de otra escultura que no se ha conservado y que debía situarse en un pequeño sacellum en la parte central del patio interno de los Horrea Agrippiana, dedicada por tres curatores de un collegium en honor a otros comerciantes relacionados con los horrea (AE 1915, 97; AE 1923, 57; AE 1927, 97) (Rickman 1971: 312-315; Salido 2012: 315).

${ }^{47}$ Resulta difícil discernir entre horrea de titularidad privada y pública mediante la simple mención de un horreum concreto o de la dedicación de un trabajador. los pobres. Así se manifiesta en la conmemoración del obispo de Tarragona, Sergio, realizada a mediados del siglo VI en verso y en el que se dedica más espacio a las gestas espirituales que mundanas y a su carácter como hombre de Iglesia, benefactor de los pobres (repperit alimentum $)^{48}$.

En Hispania se testimonia la edificación de un almacén en el año 387 d. C. en Oretum (Granátula de Calatrava, Ciudad Real $)^{49}$ mencionado como horreus (Arce 2011: 289-290). Esta inscripción menciona el nombre del contratista que certifica la obra (ex officina Homoni), su propietario (Vasco) y los funcionarios encargados de su administración: los magistri y el scriba que anotaba la cantidad de grano almacenado en el horreum. Desconocemos si las provisiones conservadas en el interior del horreum serían administradas y controladas por la Iglesia, pero no deja de llamar la atención la inclusión de la fórmula in Christo.

A tenor de la información disponible, resulta difícil confirmar el papel de la Iglesia en la recaudación de los impuestos y en el control de las actividades agrarias a lo largo del siglo IV d.C. en Hispania. En cambio, algunos testimonios procedentes de algunas villae permiten suponer un predominio del control eclesiástico en la producción agrícola. Hasta el momento se había testimoniado la producción vitivinícola bajo la responsabilidad eclesiástica en ámbito urbano tarraconense (Peña 2010: 188). Los últimos descubrimientos realizados nos permiten subrayar la importancia de la producción cerealística y su almacenamiento bajo el amparo de la Iglesia en la villa romana de El Saucedo (Toledo). Durante finales del siglo V d.C. y comienzos del siglo VI d.C., el oecus de la villa altoimperial se reforma y transforma en un enorme horreum con pavimento sobreelevado, al mismo tiempo que el salón distribuidor de las antiguas termas pasa a convertirse en basílica cristiana (Castelo et alii 2006). Esta relación espacial tan estrecha entre basílica y horreum nos informa muy posiblemente sobre la percepción de los recursos agrícolas en el

\footnotetext{
${ }^{48}$ Sollers magnanimus pius ingenio cato / hic quiescit in tumulo Sergi(u)s pontifex s(an)c(tu)s / qui sacri labentia restaurans culmina templi / haud procul ab urbe construxit cenobium $\mathrm{s}(\mathrm{an}) \mathrm{c}(\mathrm{t})$ is / [hunc] pauperes patrem hunc tutorem hab $(\mathrm{u})$ ere pupilli / vidus solamen captibis pretium / esurien(tibu)s repperit alimentum / profluus in lacrimis depulit contagia carnis / cunctis carissimus exuberanti gratia pollens / parcus in abundantia locuplex egentibus vixit / septies denos pr(a) esentis (a)evi peragens annos / tria sacer pontifex pariterq(ue) septena / religiosae vit(a)e explevit tempor(e) lustra (RIT 939; AE 1997, 963).

${ }^{49}$ Ex officina Homoni / utere felix Vasconi / in Chr(isto) proc(urante) Tiberiano / factus est horreus / d(omino) n(ostro) Valentiniano Aug(usto) / ter et Eutropio v(iro) c(larissimo) / cons(ulibus) scrib(ente) Elefanto / [- - - e]t VI[- - - ] et Neb[- -] (CIL II 3222).
} 
almacén vinculado a los dominios territoriales de la basílica cristiana. Estos datos nos desvelan, por tanto, una realidad que estaba empezando a cambiar y en el que el dominio eclesiástico se fortalece en el campo económico del decadente Imperio romano.

\section{BIBLIOGRAFÍA}

Adserias Sans, M., Pociña López, C. y Remolá Allverdú, A. 2000: "L'hábitat suburbà portuari al sector afectat pel peri 2 (Jaume, 1- Tabacalera)", J. Ruiz de Arbulo (ed.), Tarraco 99. Arqueologia d'una capital provincial romana. Documents d'arqueologia clàssica 3,Tarragona, 137-154.

Aguilar Saenz, A. y Guichard, P. 1993: Villas Romaines d'Estrémadure. Doña María, La Sevillana et leur environnement, Madrid.

Alkain, P. 2009/2010: “Aportaciones al conocimiento de las primeras etapas de ocupación de la aglomeración urbana romana de Oiasso, siglos I a.C. y I a.D. Los materiales itálicos de la excavación de BidasoaSantiago, Irún (Gipuzkoa)", Arkeolan 16, 29-38.

Alzon, C. 1964: Problèmes relatifs à la location des entrepôts en droit romain, Paris.

Arce, J. 2006: "Villae en el paisaje rural de Hispania romana durante la Antigüedad tardía", A. Chavarría, J. Arce y G. P. Brogiolo (eds.), Villas tardoantiguas en el Mediterráneo Occidental, Madrid, 17-35.

Arce, J. 2011: "Horrea y aprovisionamiento en Hispania (siglos. IV-VI)", J. Arce y B. Goffaux (eds.), Horrea d'Hispanie et de la Méditerranée romaine, Madrid, 225- 261.

Babled, H. 1892: De la cura annonae chez les Romains, Paris.

Beltrán Lloris, M. 1982: La Arqueología de Zaragoza. Últimas investigaciones, Zaragoza.

Beltrán, A. y Beltrán, M. 1989: "Hipótesis sobre la función del gran edificio de adobe de Contrebia Belaisca (Botorrita, Zaragoza)", XIX Congreso Nacional de Arqueología, vol. II, Zaragoza, 353-359.

Bustamante Álvarez, M., Salido Domínguez, J. y Gijón Gabriel, M. E. 2012: "Panaderías y pastelerías en Hispania", D. Bernal y M. Bustamante Álvarez (eds.): Artifices Idoneos. Artesanos, talleres y manufacturas en Hispania, Mérida, en prensa.

Cagnat, R. 1916: L'annone d'Afrique, París.

Cardoso, G. y Encarnaçao, J. D. 1992-1993: “A villa romana de Freiria e o seu enquadramento rural", Studia Historica. Historia Antigua 10-11, 203-217.

Castelo, R., Bango, C., López, A. y Aguado, M. 2006: "El Saucedo (Talavera la Nueva, Toledo). Un ejem- plo de villa bajoimperial en la provincia de la Lusitania", A. Chavarría, J. Arce y G. P. Brogiolo (eds.), Villas Tardoantiguas en el Mediterráneo Occidental, Anejos Archivo Español de Arqueología 39, Madrid, 173-196.

Cerrillo Martín de Cáceres, E., Alvarado Gonzalo, M., Cerrillo Martín de Cáceres, F. J., Herrerea García, G. y González Luceño, M. A. 1988: “Excavaciones en la villa romana de Monroy (Cáceres), 19811985”, Extremadura Arqueológica 1, 167-186

Cerrillo Martín de Cáceres, E. 2006: "La villa romana de Monroy", A. Chavarría, J. Arce y G. P. Brogiolo, (eds.), Villas Tardoantiguas en el Mediterráneo Occidental. Anejos Archivo Español de Arqueología 39, 197-206.

Chaouli, M. 2005: "Les nundinae dans les grands domaines en Afrique du Nord à l'époque romaine", Antiquités Africaines 38-39 (2002-2003), 375-386.

D’ors, A. 1953: Epigrafía jurídica de la España romana, Madrid.

Dardaine, S. y Pavis D’Escurac, U. 1986: "Ravitaillement des cités et evergetisme annonaire dans les provinces occidentales sous le haut-Empire", Ktema 11, 291- 302.

De Ruyt, C. 1983: Macellum. Marché alimentaire des Romains, Lovaina.

Drake, B. 2006: "Excavación arqueológica en el yacimiento de los sectores plataforma norte y sur del yacimiento 12 B (Carrascalejo)", Extremadura arqueológica 10, 213-232.

Dubouloz, J. 2008: "Propriété et explotation des entrepôts à Rome et en Italie (Ier-IIIe siècles)", Mélanges de l'École française de Rome. Antiquité 120 (2), 277-294.

Dubouloz, J. 2011: La propriété inmobilière à Rome et en Italie, Ier-Ve siècles, Bibliothèque des Écoles Françaises d'Athenes et de Rome 343, Roma.

Erice, R. 2011: "El puerto fluvial de Caesaraugusta", J. Arce y B. Goffaux (eds.), Horrea d'Hispanie et de la Méditerranée romaine, Madrid, 143-158.

Etienne, R. 1990: Les villas romaines de Sao Cucufate, París.

Fernández Ochoa, C. 2000: El lenguaje de las piedras. La recuperación del patrimonio arqueológico de Gijón, Gijón.

Fernández Ochoa, C. y Gil Sendino, F. 2008: "La villa romana de Veranes (Gijón, Asturias) y otras villas de la vertiente septentrional de la cordillera cantábrica”, C. Fernández Ochoa, C., García-Entero, V. y Gil Sendino, F., (eds.), Las villae tardorromanas en el Occidente del Imperio. Arquitectura y función. IV Coloquio Internacional de Arqueología en Gijón 2007, Gijón, 435-479. 
Fernández Ochoa, C., Gil Sendino, F. y Orejas Saco del Valle, A. 2004: "La villa romana de Veranes. El complejo rural tardorromano y propuesta de estudio del territorio", Archivo Español de Arqueología 77, 197-220.

Fernández Ochoa, C., Gil Sendino, F., Salido Domínguez, J. y Zarzalejos Prieto, M. 2013: El horreum de la villa romana de Veranes (Gijón, Asturias). Primer testimonio material de los hórreos de Asturias, Madrid.

Fernández Ochoa, C., Morillo, A. y Salido Domínguez, J. 2011: "Ciudades amuralladas y annona militaris durante el Bajo Imperio en Hispania. Una cuestión a debate", J. Arce y B. Goffaux (eds.), Horrea d'Hispanie et de la Méditerranée romaine, Madrid, 265-286.

Fita Colomé, F. 1898: "Inscripciones romanas de Isona", Boletín de la Real Academia de la Historia 32, 532-536.

Gabba, E. 1988: Del buon uso della ricchezza, Milano.

Giliberti, G. 1984: Legatum kalendarii. Mutuo feneratizio e struttura contabile del patrimonio nell'età del Principato, Napoli.

Goffaux, B. 2003: "Evergétisme et sol public en Hispanie sous 1'Empire", Mélanges de la Casa de Velázquez 33.2, 225-247.

Gracia Alonso, F. 2009: "Producción y almacenamiento de excedentes agrícolas en el NE peninsular entre los siglos VI y II a.C. Análisis crítico”, R. García Huerta y D. Rodríguez (eds.), Sistemas de almacenamiento y conservación de alimentos entre los pueblos prerromanos peninsulares, Humanidades 103, Cuenca, 9-72.

Henzen, W. 1874: Acta Fratum Arvalium, Berlin.

Lara, F. 1973: Epigrafía romana de Lérida, Lérida.

Le Roux, P. 1988: "L'huile de Betique et le prince sur un itineraire annonaire", Hommage Robert Etienne, Paris, 247-272.

Leveau, P. 1983-1984: "Le rapport ville-campagne dans 1'Antiquité romaine: villa, ville, village", Annales. Économies, Sociétés, Civilisations 38.4, 920-942.

Macias, J. M. 2011: "Horrea y estructuras de almacenamiento en la ciudad y territorio de Tarraco: una primera aproximación", J. Arce y B. Goffaux (eds.), Horrea d'Hispanie et de la Méditerranée romaine, Madrid, 185-200.

Maloney, S. y Hale, J. 1996: "The villa of Torre de Palma (Alto Alentejo)", Journal Roman Archaeo$\log y$ 9, 275-294.

Martínez, J. I. 2006: "El vocabulario de los asentamientos rurales (siglos I-IX d.C.): Evolución de la terminología”, A. Chavarría, J. Arce y G. P.
Brogiolo (eds.), Villas Tardoantiguas en el Mediterráneo Occidental, Anejos Archivo Español de Arqueología XXXIX, 113-132.

Medrano Marqués, M., Díaz, Mª . A. y Tramullas Saz, J. 1991: "Reconstitución del edificio monumental de Contrebia Belaisca (Botorrita, Zaragoza)", Complutum 1, 281-292.

Melchor Gil, E. 1992: Evergetismo en la Hispania Romana, Tesis doctoral de la Universidad de Córdoba, Córdoba.

Melchor Gil, E. 1993: "Evergetismo annonario y 'Alimenta' en Hispania romana”, Veleia 10, 95-104.

Monteix, N. 2008: "La conservation des denrées dans l'espace domestique à Pompéi et Herculanum", Mélanges de l'École française de Rome. Antiquité 120 (1), 123-138.

Morillo, A. y Salido Domínguez, J. 2010: "El aprovisionamiento del ejército en Hispania. Transporte, almacenaje y redistribución", J. J. Palao (ed.), Militares y civiles en Roma. Dos mundos diferentes, dos mundos unidos, Colección Aquilafuente 163, Salamanca, 135-164.

Moutoso Batata, C. A. 2006: Idade do ferro e romanização entre os rios Zêzere, Tejo e Ocreza, Lisboa.

Navarro Caballero, M. 1997: "Les dépenses publiques des notables des cités en Hispania Citerior sous le Haut-Empire", Revue des études anciennes 99 (1-2), 109- 140.

Nolla, J. M., Palahí, L. y Vivo, J. 2010: De l'oppidum a la civitas. La romanització inicial de la Indigècia, Girona.

Olmedo Grajera, A. B. y Vargas Calderón, J. 2004: 'Una 'qarya' emiral de la 'kura' de 'Marida': intervención arqueológica en la finca 'Royanejos"”, Mérida. Excavaciones arqueológicas 10, 15-46.

Ordóñez Agulla, S. y González Acuña, D. 2011: “Horrea y almacenes en Hispalis: evidencias arqueológicas y evolución de la actividad portuaria", J. Arce y B. Goffaux (eds.), Horrea d'Hispanie et de la Méditerranée romaine, Madrid, 159- 184.

Ordoñez Agulla, S. y Saquete Chamizo, J. C. 2009: “Una dedicación votiva 'ex multis Pistorum' hallada en la Bética", Habis 40, 197-204.

Papi, E. y Martorella, F. 2007: "Il grano della Tingitana”, E. Papi (ed.), Supplying Rome and the Empire (Siena-Certosa, 2004), Journal of Roman Archaeology Supplementary Series 69, Portsmouth, 85-96.

Peña Cervantes, Y. 2010: Torcularia. La producción de vino y aceite en Hispania, Documenta 14, Madrid.

Pérez Zurita, A. D. 2011: La edilidad y las élites locales en la Hispania romana. La proyección de una magistratura de Roma a la administración imperial, Córdoba/Sevilla. 
Pomey, P. y Tchernia, A. 1978: "Le tonnage maximum des navires de commerce romains", Archaeonautica 2 (2), 233-251.

Pons, J. 1979: "Propiedad privada de la tierra y comunidades campesinas pirenaicas: Análisis de una sentencia judicial del año 193", Memorias de historia antigua 3, 111-124.

Prevosti, M. 2011: "El sistema econòmic dels establiments de l'ager Tarraconensis", M. Prevosti y J. Guitart i Duran (eds.): Ager Tarraconensis 2, El poblament, Documenta 16, Tarragona, 405-454.

Purcell, N. 1995: "The Roman villa and the landscape of production", T. J. Cornell y K. Lomas (eds.), Urban Society in Roman Italy, London, 151-179.

Ramírez Sádaba, J. L. 2003: “Anexo C. Epigrafía”, J. M. Álvarez y T. Nogales (eds.), Forum Coloniae Augustae Emeritae. 'Templo de Diana', Mérida, 351-396.

Remesal, J. 1986: La annona militaris y la exportación de aceite bético a Germania, Madrid.

Ribera i Lacomba, A. 2011: "Los horrea de Valentia. De la República al Imperio”, J. Arce y B. Goffaux (eds.), Horrea d'Hispanie et de la Méditerranée romaine, Madrid, 201-224.

Rickman, G. 1971: Roman granaries and store buildings, Cambridge.

Rodríguez Gutiérrez, O. 2007: "Ilipa Romana: la configuración de la ciudad a partir de los nuevos datos arqueológicos", E. Ferrer, A. Fernández, J. L. Escacena y A. Rodríguez (eds.), Ilipa Antiqua. De la Prehistoria a la Época Romana. I Congreso de Historia de Alcalá del Río, vol. 1, Sevilla, 2007, 171-191.

Rodríguez Neila, J. F. 1975: "Notas sobre las 'annonae' municipales de Hispania”, Hispania Antiqua 5, 315-326.

Rodríguez Neila, J. F. 1989: "Liberalidades públicas y vida municipal en la Hispania Romana”, Veleia 6, 135-170.

Román Rodríguez, J. M. 2001: "El almacenamiento de grano en Carmona: el horreum de San Blas", A. Caballos (ed.), Carmona Romana. Actas del II Congreso de Historia de Carmona, 233-250.

Rougé, J. 1966: Recherches sur l'organisation du commerce maritime en Méditerranée sous l'Empire romain, París.

Salido Domínguez, J. 2003-2004: "La documentación literaria aplicada al registro arqueológico: las técnicas de construcción de los graneros romanos rurales", Espacio, Tiempo y Forma. Serie I: Prehistoria y Arqueología 16-17, 463-478.

Salido Domínguez, J. 2008: "La investigación sobre los horrea de época romana: balance historiográfico y perspectivas de futuro", Cuadernos de Prehistoria y Arqueología de la Universidad Autónoma de Madrid 34, 105-124.

Salido Domínguez, J. 2008b: "Los sistemas de almacenamiento y conservación de grano en las $v i$ llae hispanorromanas", C. Fernández Ochoa, C., García-Entero, V. y Gil Sendino, F., (eds.), Las villae tardorromanas en el Occidente del Imperio. Arquitectura y función. IV Coloquio Internacional de Arqueología de Gijón, Gijón, 693-706.

Salido Domínguez, J. 2009: "Los graneros militares romanos de Hispania", A. Morillo, N. Hanel y E. Martín (eds.), Limes XX. Estudios sobre la Frontera Romana, Anejos de Gladius 13, volumen 2, Madrid, 679-692.

Salido Domínguez, J. 2011: Horrea Militaria. El aprovisionamiento de grano al ejército en el Occidente del Imperio Romano, Anejos de Gladius 14, Madrid.

Salido Domínguez, J. 2011b: "El almacenamiento de cereal en los establecimientos rurales hispanorromanos", J. Arce y B. Goffaux (eds.), Horrea d'Hispanie et de la Méditerranée romaine, Madrid, 127-142.

Salido Domínguez, J. 2012: "Manifestaciones religiosas y espacios sacros en los Horrea del Occidente del Imperio Romano", Madrider Mitteilungen, 53, 310-341.

Salido Domínguez, J. 2012b: "The Grain Supply for the Roman Army in Republican Hispania". XXI Limes Congress. Newcastle, British Archaeological Reports, British Series, en prensa.

Serrano-Vicente, M. 2006: Custodiam Praestare. La prestación de custodia en el derecho romano, Sevilla.

Sirks, A. J. B. 1991: Food for Rome: the legal structure of the transportation and processing of supplies for the imperial distributions in Rome and Constantinople, Amsterdam.

Speidel, M. y Dimitrova-Mileva, A. 1978: "The Cult of the Genii in the Roman Army and a new military deity", Aufstieg und Niedergang der römischen Welt 16.2, 1542- 1555 .

Torrecilla Aznar, A. 2007: Los macella en la Hispania romana. Estudio arquitectónico, funcional y simbólico. Tesis doctoral inédita de la UAM, Madrid.

Tran, N. 2008: "Les collèges d'horrearii et de mensores, à Rome et à Ostie, sous le Haut-Empire", Mélanges de l'École française de Rome. Antiquité 120 (2), 295-306.

Urteaga, M. 2003: "El puerto romano de Oiasso (Irún) y la desembocadura del río Bidasoa", C. Fernández Ochoa (ed.), Gijón puerto romano, Gijón, 193-211. 
Urteaga, M. y Alkain, P. 2009: "L'horreum du Port d'Oiasso', Colloque international', Entrepôts et systèmes de stockage dans le monde gréco-romain antique. Etat des lieux, 18-19-20 mars 2009. Résumés des Communications, Aix-en-Provence, 10.

Vargas Calderón, J. y Matesanz Vera, P. 2006: "Excavación arqueológica yacimiento número 6-8: Plasencia sur - Cañaveral este". Extremadura arqueológica 10, 115- 144.
Virlouvet, C. 2011: "Les entrepôts dans le monde romain antique, formes et fonctions. Premières pistes pour un essai de typologie", J. Arce y B. Goffaux (eds.): Horrea d'Hispanie et de la Méditerranée romaine, Madrid, 7-22.

VV. AA. 2010: Time of changes. In the beginning of the Romanization, Studies on the rural world in the Roman Period 5, Girona.

Recibido: 07-02-2012

Aceptado: 29-10-2012 